Article

\title{
Stakeholder Symbiosis in the Context of Corporate Social Responsibility
}

\author{
Danli Wang ${ }^{1,2}$, Weidong Zhu ${ }^{3}$, Chao Zhang ${ }^{1, *}$, Hongyi $\mathrm{Li}^{4}$ and Yong $\mathrm{Wu}^{1}$ \\ 1 School of Management, Hefei University of Technology, Hefei 230009, China; \\ 2017010088@mail.hfut.edu.cn (D.W.); wuyong@hfut.edu.cn (Y.W.) \\ 2 School of economics, North Minzu University, Yinchan 750021, China \\ 3 The Center for Industrial Information and Economic Research, Hefei University of Technology, \\ Hefei 230009, China; zhuwd@hfut.edu.cn \\ 4 Business Administration Faculty, The Chinese University of Hong Kong, Hong Kong 999077, China; \\ hongyi@baf.msmail.cuhk.edu.hk \\ * Correspondence: zhangchao@hfut.edu.cn; Tel.: +86-186-798-502-46
}

Received: 29 October 2020; Accepted: 17 November 2020; Published: 18 November 2020

\begin{abstract}
With the rise of corporate social responsibility (CSR) and the great changes of the organization scale of the modern enterprise, it is difficult to maintain an ideal development only by maximizing the equity of shareholders. The co-governance of stakeholders can meet the interests of all stakeholders, which is the embodiment of corporate social responsibility in corporate governance. The creation and sharing of enterprise values are the foundation of the coexistence of stakeholders. A rational allocation of the limited enterprise values among stakeholders plays a crucial role in balancing their relationship and realizing the sustainable development of the enterprise. Based on the application of corporate social responsibility in stakeholder governance, this paper constructs a stakeholder symbiosis evolution model with the help of symbiosis theory. By solving the differential equation, the symbiotic evolution path of stakeholders is analyzed. The dynamic mechanism of stakeholder Symbiosis evolution is analyzed by using the system analysis method and evolution theory. The dynamic mechanism of the population evolution of stakeholders is represented in an original graphical manner to describe the symbiotic evolution process of stakeholders. Lastly, we use the numerical simulation method to simulate different symbiosis models which are reflected by different symbiosis coefficients. It is concluded that the symmetric mutual benefit symbiosis model is the most effective model to reflect corporate social responsibility.
\end{abstract}

Keywords: corporate social responsibility (CSR); stakeholders theory; symbiosis theory; symmetric mutual benefit symbiosis model; symbiotic evolutionary model; evolutionary dynamic mechanism

\section{Introduction}

In the 1960s, great changes have taken place on the organizational scale of American enterprises. Corporate social responsibility and social ethics have attracted much attention [1,2]. It is difficult for enterprises to maintain the uniqueness of shareholders' rights and interests established by commercial law and company law [3]. Stakeholder theory can solve this problem. Stakeholder theory emphasizes that all stakeholders participate in the creation of enterprise value and the value distribution among stakeholders should depend on the contribution of the stakeholders [4]. Stakeholder theory is more suitable for the development of modern enterprises compared with the model of shareholder-centered governance. Therefore, the model of the co-governance guided by the stakeholder theory has drawn more attention from scholars [5,6]. In the co-governance of stakeholders, a key issue is how to balance the interests of stakeholders. Scholars researched this issue from the perspective of symbiosis to 
construct the symbiotic governance model of stakeholders [7]. The concept of symbiosis originates from biology. It is used to describe the relationship between existing symbiotic units under a certain model and state of the resource environment. The operation law of modern management has similar symbiotic characteristics with the biological community in the natural ecosystem. Yuan Chunqing, a Chinese scholar, first applied the symbiosis method completely in his book Symbiosis Theory and Small Economy. He systematically developed symbiosis theory from the perspective of economics and introduced it into the study of the small economy in China. Since then, the symbiosis theory has been widely used in social and economic research.

The existing research on economic management with symbiosis theory focuses on the symbiosis between enterprises or industries. The researches involve industrial symbiosis [8-10]. Symbiotic development of productive service industry and manufacturing industry [11]. The symbiosis of innovation ecosystem [12] and so on. The logistic growth model proposed by Dutch biologist Verhulst in the mid-19th century is mostly used to describe the trajectory of symbiotic evolution among the units in the symbiotic relationship. However, there is little literature on the study of internal economic relations of enterprises based on the symbiosis theory. With certain constraints, the process of co-creation and sharing of enterprise value among stakeholders can be studied by referring to the symbiotic model in biology. However, the symbiotic relationship and the symbiotic evolutionary process in the economic system is more complicated compared with that in biology. A symbiotic relationship in the economic system is mainly manifested by the characteristics of nonlinear and disorder in the interaction among symbiotic units [13]. Around the core issues of stakeholder governance theory and symbiotic evolution theory, the topics like the measurement of the stakeholder population density in symbiotic development, the description of the symbiosis model, the dynamic mechanism of the symbiotic evolution, and the evolution of symbiotic environmental capacity and population density under the established mechanisms can be studied. The study on these topics will help improve and refine the stakeholder theory.

The traditional unilateral governance model of shareholders takes the profit index as the target variable. In the symbiotic governance model, value-added is regarded as the value variable for the enterprises. Value-added can reflect the object attribute, multiple subject attribute, and social attribute of the value [14]. Value-added conforms to the logic of the symbiotic governance of stakeholders and reflects the corporate social responsibility. At the same time, the stakeholders get income by devoting their resource endowment. In the symbiotic governance model, the income of all stakeholders should change with time and form a symbiotic evolution mechanism. In this paper, value-added is adopted as the quantification of enterprise value. The incomes of the value-added of stakeholders are used as the index for population density. By taking the income of the value-added as the indication of population density, the performances of stakeholders in the symbiosis process can also be shown, which meets the purpose of this research.

The application of symbiosis theory in management mainly focuses on the macro level. As the most basic part of the economic system, the sustainable development of enterprises is related to the sustainable development of the economy. The distribution of enterprise value among stakeholders plays an important role if the enterprise pursues long-term sustainable development. Although there are many types of research on value distribution, it is rare to incorporate symbiosis theory and evolution thought into the research of enterprise value distribution.

This study contributes to the literature in three ways. Firstly, based on stakeholder theory and symbiosis theory, we construct a symbiotic evolution model of stakeholders to describe the development trajectory of stakeholders in the value creation process. In this model, the value-added income of stakeholders is selected as the index that could reflect the population density of stakeholders. Different symbiotic coefficients represent different symbiotic modes. Different symbiosis modes are given corresponding management significance. The model can be used as a tool to judge whether the symbiosis model of stakeholders in the enterprise conforms to the goal of corporate social responsibility. Secondly, we introduce the theory of evolution into the study and perform a further derivation 
on the symbiotic evolution model between shareholders and employees on a mathematical level, in which the dynamic mechanism of the symbiosis and evolution process of stakeholders is shown, thus providing theoretical supports for the model. Lastly, based on the analysis of the system stability of the symbiotic evolution model of shareholders and employees, the different symbiotic modes are simulated. By simulating the development process of symbiotic units under various symbiotic modes, the influence of different modes on the environmental capacity are discussed, and finally, the optimal symbiotic model for stakeholders is derived.

In summary, this paper integrates stakeholder theory, symbiosis theory, and evolution theory into a research framework. From the perspective of corporate social responsibility, the stakeholder symbiotic evolution model innovates the research of stakeholder symbiosis governance.

The rest of the paper is organized as follows. In Section 2 we discussed the most related literature in this area. In Section 3 we constructed the symbiotic evolution model of stakeholders based on the logistic growth model. On this basis, we gave a practical explanation of the different symbiotic model of stakeholders. In Section 4 we summarized the dynamic mechanism of stakeholder symbiotic evolution by deducing the formula of stakeholder symbiotic evolution. The dynamic mechanism is the theoretical support for the symbiotic evolution of stakeholders. In Section 5 we simulated different symbiosis mods. And the last section is the conclusions of this paper.

\section{Literature Review}

\subsection{Corporate Social Responsibility and Stakeholder Theory}

The relationship between corporate social responsibility and stakeholder theory has always been controversial. Some scholars considered that CSR was competitive with stakeholder theory [15]. Others saw the relationship between CSR and stakeholder theory was complementary [16]. This paper adopts the viewpoint of [17]: Stakeholder theory emphasizes the responsibility to all stakeholders, which can be defined in corporate social responsibility. In addition, according to the pyramid of corporate social responsibility, moral management should meet the interest needs of all stakeholders [18], rather than merely maximize the interests of shareholders as the goal of corporate development. According to [19], corporate social responsibility activities can well motivate employees to participate in the work. Stakeholder theory emphasizes that all stakeholders participate in the creation of enterprise value and the value distribution among stakeholders should depend on the contribution of the stakeholders. From this point of view, the implementation goal of CSR is consistent with the guiding goal of the stakeholder theory. From the perspective of [20], CSR is a tool to implement stakeholder theory. In the study on the implementation of CSR of EU member states, scholars found that enterprises that can implement CSR well have better performance [21]. From the perspective of consumers as a stakeholder, when a CSR is consistent with the consumers' moral foundations, and the enterprise persistently adheres to the CSR, consumers will show positive responses to the enterprise, such as gaining consumers' word-of-mouth and loyalty [22,23]. According to [24], reputation is a very important factor for an enterprise to win customers, corporate social responsibility is an important tool to promote the reputation and enhance the brand [25].

\subsection{Stakeholder Symbiotic Governance}

In general, stakeholders refer to all groups or individuals that affect the realization of goals of a certain organization or are affected by the realization of goals of a certain organization [26]. For an enterprise, the stakeholders include shareholders, employees, creditors, suppliers, consumers, governments, and communities. There are two modes for stakeholder governance: one is the traditional management model in which shareholders exercise governance unilaterally to maximize the interests of shareholders by coordinating the relationship among stakeholders through communication and appropriate economic incentives [27-30]. However, it is difficult to balance and guarantee the interests of all stakeholders with this model. Therefore, a significant improvement to corporate performance in 
the management practice can barely be achieved. The second one is called stakeholder participation governance model, which is composed of stakeholder joint governance [31] and key stakeholder governance [32,33]. Shareholders belong to the overall scope of stakeholders in this model. The goals of this model are to realize a rational interest allocation among all stakeholders and to maximize the enterprise value in the end. This turns out to be a better governance model [34], and it has been applied by many companies in practice.

In the studies of joint governance of stakeholders, there are still many aspects that need to be improved, such as the selection of stakeholder objective function and the allocation demands of general stakeholders. To improve the theory of joint governance of stakeholders, many scholars have introduced the concept of "symbiosis" from biology into their researches and constructed the model of stakeholder governance from the perspective of symbiosis. symbiosis degree and symbiosis coefficient were used to describe the co-governance model of core stakeholders. Scholar [35] established an omnibearing and multi-level symbiotic network that includes shareholders, enterprises, government, and managers. Other scholars classified stakeholders and then established the stakeholder model and group-interest allocation model from the perspective of multiple capital symbiosis [36], which includes finance capital, human capital, social capital, organization capital, and ecological capital [37-39]. These studies have become the foundation of the symbiotic governance model. Scholars [7] established the Symbiosis Evolution Model of core stakeholders, analyzed the symbiosis development model of labor and capital explicitly, and fitted the model parameters with Haier data, which verified the rationality and necessity of building the symbiosis model of labor and capital.

\subsection{Stakeholder Symbiosis and Value-Added Theory}

There is a natural inter-connectivity between value-added theory and the Stakeholder theory. To share corporate value is the motivation for stakeholders to contribute their resources and participate in corporate governance. Value-added is the newly created value in the production process of an enterprise. It reflects the contributions to the enterprise and the corresponding obtained benefits of all participants inside and outside the enterprise. It is a quantitative index of stakeholder theory.

Many scholars believe that value-added is more suitable as a value variable and a target variable of an enterprise than profit [40,41]. Moreover, value-added provides more information for stakeholders than profit [42]. Scholars [43] found that value-added could satisfy the demands of value-co-creation of stakeholders. Besides, value-added reflects the subject-object relationship in the value creation process. Compared with the profit, value-added reflects corporate incomes in a more general way [44]. Meanwhile, using value-added to assess the corporate value can alleviate the hostility of employees and inspire their enthusiasm for the work. Some scholars believed that the calculation of profit is affected by many factors with larger uncertainties. It is difficult to precisely show the business results of an enterprise by using its profit. However, using value-added can avoid these defects. It is also an ideal index to show the operation status of enterprises. The allocation of value-added is an important method for enterprises to motivate the stakeholders, which can give full play to the function of incentive compatibility. Moreover, rational allocation is the foundation of cooperation in an enterprise. It can lead to a good partnership between stakeholders [45]. Based on the allocation of value-added, scholars [45] have established a research framework that can be used to study the non-competitive market influence factors that affect the allocation of value-added of stakeholders. Reasonable allocation of value-added is conducive to the creation of enterprise value as well, this leads to a harmonious environment for stakeholders to create and share the enterprise value together.

\section{Modeling and Methods}

The logistic growth model is a population evolution model based on exclusive resource consumption, which is used to describe the evolution of species population over time. In the economic field, the relationship among stakeholders in an enterprise is similar to that of population symbiosis in the ecosystem. The enterprise provides the living environment and resource for stakeholders, 
on the other hand, the stakeholders create and share the enterprise value by undertaking different responsibilities to promote the development of the enterprise. Therefore, this paper constructs the enterprise stakeholder growth model based on the logistic growth model. In the study of the symbiotic relationship of stakeholders, we mainly consider the population density, symbiotic model, and the evolution of stakeholder groups under different symbiotic modes.

In the studies of symbiosis relations in the economic field, the population density is usually represented by several features of symbiosis units. For example, scholars [9] regarded GDP as the population density of industry. This paper takes the income of value-added $V$ as the population density for stakeholders and takes the maximum income of value-added that an enterprise can provide to stakeholders as the environmental capacity of the stakeholders. The natural growth rate $r$, which reflects the change of population density of stakeholders, is a constant if we neglect the change of value-added caused by exogenous factors such as the economic environment and enterprise system. With the increase of the population density of stakeholders, here is the income of value-added, the population number is density-dependent. Limited by the environment carrying capacity, the population density of stakeholders will inevitably reach the maximum, which means that value-added allocated to stakeholders has a maximum value. Therefore, the development of stakeholders in an enterprise conforms to the logistic growth model, which can be used to reflect the growth process of the stakeholder population in the enterprise.

\subsection{Logistic Growth Model of Stakeholders}

Assuming population density (income of value-added) of stakeholder $i$ in the enterprise is represented by $V_{i}$ which can be denoted as a function of time, $V_{i}(t)$. With the development of time, factors such as technology, innovation, information, and the market environment will affect the population density of stakeholders. The initial population density is $V_{i 0}$. The natural growth rate is $r_{i}$, and the environmental capacity of the population (the maximum added-value that the enterprise can allocate to the stakeholders under the given conditions) is $K_{i}$. Then the logistic growth equation of stakeholders is as follows:

$$
\left\{\begin{array}{c}
\frac{d V_{i}(t)}{d t}=r_{i} V_{i}(t)\left[1-\frac{V_{i}(t)}{K_{i}}\right] \\
V_{i}\left(t_{0}\right)=V_{i 0}
\end{array}\right.
$$

Equation (1) is a first-order ordinary differential equation (ODE) with separable variables, and its solution is as follows:

$$
V_{i}(t)=\frac{K_{i}}{1+\left(\frac{K_{i}-V_{i 0}}{V_{i 0}}\right) e^{-r_{i} t}}
$$

When $t \rightarrow+\infty, V_{i}(t) \rightarrow K_{i}$. The population density will not be affected by the initial value and tends to the environment capacity value $K_{i}$. In a limited time, when $0<V_{i}(t)<K_{i}$, the second derivative of $V_{i}(t)$ is $\frac{d^{2} V_{i}(t)}{d t^{2}}=r_{i}\left[1-\frac{2 V_{i}(t)}{K_{i}}\right] \frac{d V_{i}(t)}{d t}$. When $V_{i}(t)<\frac{K_{i}}{2}, \frac{d^{2} V_{i}(t)}{d t^{2}}>0, V_{i}(t)$ is a concave function in $\left[0, \frac{K_{i}}{2}\right]$, and the increase of population density is not limited by the Environment. When $V_{i}(t)>\frac{K_{\mathrm{i}}}{2}$, we can get $\frac{d^{2} V_{i}(t)}{d t^{2}}<0$, then $V_{i}(t)$ is a convex function in $\left[\frac{K_{i}}{2}, K\right]$. Due to the increase of population density, the competition within the population is intensified, and the natural growth rate $r_{i}$ is then limited. The growth rate slows down until it reaches the extreme $K_{i}$. The logistic growth model of stakeholder $i$ can be shown in Figure 1.

As shown in Figure 1, when the population density of a stakeholder is less than $\frac{K_{i}}{2}$, the density is in an accelerating growth period. When the population density is more than $\frac{K_{i}}{2}$, its growth rate slows down but the population density is still increasing until it reaches $K_{i}$. This process can be understood in the perspective of value-added income as: when the internal and external resources and environment of an enterprise remain unchanged, the new value that the enterprise can create is determined, and the value-added income of each stakeholder has the maximum value due to the limited total value-added 
of the enterprise. In a certain period, if we ignore the overall growth of the enterprise brought by external factors such as economic environment, economic system, and innovation, the value-added income of all stakeholders will go through the processes of starting, accelerating growth, growth rate slowing down, and finally reach saturation.

\section{$V_{i}(t)$ (population density)}

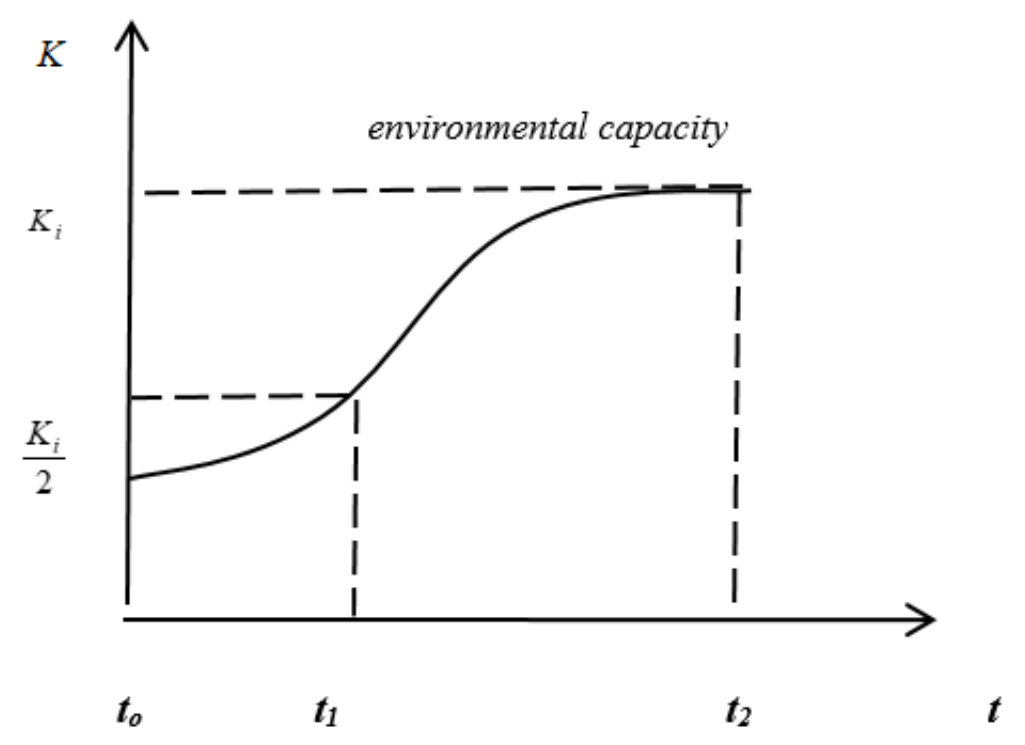

Figure 1. Logistic growth curve of stakeholder population.

\subsection{Symbiotic Evolution Model of Stakeholders}

Stakeholders provide resources and make use of their expertise to promote the development of an enterprise. In this process, the scale of the enterprise is expanded with an increasing newly created value. Therefore, the value-added that can be allocated to all stakeholders is also increased. This means that the symbiosis development of stakeholders makes the environmental capacity for each population increase, and the population density (value-added incomes) of stakeholders is also increased. This can be explained as such that the symbiosis process of stakeholders has certain impacts on the environment capacity, at the end, their population density is affected as well. In this paper, we use a less stringent constraint on population density in the logistic growth model to promote population growth. In practice, different stakeholders might be affected by different symbiotic mechanisms. Meanwhile, the extent of the influence of the symbiotic process on stakeholders might also be different. Therefore, the effect of symbiosis on various groups of stakeholders is nonlinear. To facilitate the research, this paper first selects two important groups of stakeholders, shareholders, and employees, to construct a symbiotic evolution model and study their symbiosis model. Then we extend the results to general stakeholders. The symbiotic evolution model of shareholders and employees is as follows:

$$
\left\{\begin{array}{l}
\frac{d V_{1}(t)}{d t}=r_{1} V_{1}\left[1-\frac{V_{1}}{K_{1}}+\alpha \frac{V_{2}}{K_{2}}\right] \\
\frac{d V_{2}(t)}{d t}=r_{2} V_{2}\left[1-\frac{V_{2}}{K_{2}}+\beta \frac{V_{1}}{K_{1}}\right]
\end{array}\right.
$$

In the equations above, the first equation is the shareholder evolution growth equation. $\alpha$ represents the coefficient of the effect of the change of employee population density on the shareholder. The second equation is the employee evolution growth equation. $\beta$ represents the coefficient of the effect of the change of shareholder population density on the employee. In symbiosis, $\alpha$ and $\beta$ are called symbiotic coefficients. According to the symbiosis theory, the symbiotic model of shareholders and employees varies with the range of $\alpha$ and $\beta$. The specific symbiosis model is shown in Table 1 . 
Table 1. Symbiosis model of shareholders and employees.

\begin{tabular}{ccc}
\hline Case & Symbiotic Coefficient & Symbiosis Model \\
\hline$(1)$ & $\alpha=\beta=0$ & independent symbiotic model \\
$(2)$ & $\alpha=0, \beta>0$ or $\alpha>0, \beta=0$ & partial benefit symbiosis model \\
$(3)$ & $\alpha=\beta>0$ & symmetric mutual benefit symbiosis model \\
$(4)$ & $\alpha>0, \beta>0, \alpha \neq \beta$ & asymmetrical mutual benefit symbiosis model \\
$(5)$ & $\alpha<0, \beta>0$ or $\alpha>0, \beta<0$ & parasitic symbiosis model \\
$(6)$ & $\alpha<0$ and $\beta<0$ & competitive symbiosis model \\
\hline & Source: authors' elaboration based on the following studies [7,12].
\end{tabular}

In case (1), when $\alpha=\beta=0$, the shareholders and the employees are in an independent symbiotic model. This means that the shareholders and the employees develop independently of each other. In the practice of management, it is unusual for shareholders and employees to be independent of each other. Because physical capital and human capital cannot exist in the enterprise alone. The independent model is not conforming with the development goal of an enterprise.

In case (2), when $\alpha=0, \beta>0$ or $\alpha>0, \beta=0$, the shareholders and the employees are in a partial benefit symbiosis model. In this model, only one of the two is benefiting, the other one is not affected. Since a coordinated allocation of the value-added is the foundation of the cooperation between different groups of stakeholders, the one who does not benefit from the symbiosis will not allow such a long-term existence of this model. Therefore, this model will inevitably lead to a loss of human capital or physical capital for an enterprise.

When $\alpha>0$ and $\beta>0$, the shareholders and the employees are in a mutually beneficial symbiosis model. According to the different conditions of mutualism, mutually beneficial symbiosis model can be divided into symmetric mutually beneficial symbiosis model and asymmetric mutually beneficial symbiosis model. When $\alpha=\beta$, as in case (3), the shareholders and the employees are in a symmetric mutually beneficial symbiosis model. In this model, the shareholders and the employees can not only benefit from each other but also have a symmetrical allocation for the value-added. Both physical capital and human capital will participate in the governance of the enterprise in coordination, which guarantees stable cooperation between shareholders and employees and improves the efficiency of enterprises, thus leads to the greatest development for enterprise value. Therefore, this model is an ideal model for an enterprise.

When $\alpha \neq \beta$, as in case (4), the shareholders and the employees are in an asymmetric mutually beneficial symbiosis model. In this model, although the shareholders and the employees can benefit from each other, the allocation of value-added is asymmetric, which means one of the two gains more value-added than the other. In the practice of enterprise management, the unilateral governance structure of shareholders often ignores the importance of employees, which leads to the asynchronous evolution of shareholders and employees. This situation is manifested as attaching more importance to physical capital than human capital or vice versa.

The fifth case represents a parasitical symbiosis model between shareholder and employee. In this model, there is no new value-added created. The value-added incomes only transfer from the shareholders to the employees or from the employees to the shareholders, which is conducive to the parasite but unfair to the development of the host. In the management practice, this kind of situation may appear in the beginning stage of symbiosis, which mainly exists when the value-added has not been generated after receiving the investment of shareholders.

There is also the competition symbiosis model between the shareholders and the employees when $\alpha<0$ and $\beta<0$, as shown in case (6). This model mainly exists among industry competitors and does not support the symbiosis development of internal stakeholders. 
Based on the above analysis, when there are $\mathrm{n}$ stakeholders in the symbiosis circle, the symbiosis growth function of each stakeholder can be described as

$$
\begin{gathered}
\frac{d V_{1}(t)}{d t}=r_{1} V_{1}\left(1-\frac{V_{1}}{K_{1}}+\sum_{j=2}^{n} \alpha_{1 j} \frac{V_{j}}{K_{j}}\right) \\
\ldots \ldots \\
\frac{d V_{i}(t)}{d t}=r_{i} V_{i}\left(1-\frac{V_{i}}{K_{i}}+\sum_{j=1, j \neq i}^{n} \alpha_{i j} \frac{V_{j}}{K_{j}}\right)
\end{gathered}
$$

Then the symbiotic evolution model of stakeholders can be expressed as follows:

$$
\frac{d V_{i}(t)}{d t}=r_{i} V_{i}\left[1-\frac{V_{i}(t)}{K_{i}}+\sum_{j=1}^{n} a_{i j} f_{i j}\left(V_{j i}\right)\right] \quad(i, j=1,2 \ldots n, i \neq j)
$$

where $a_{i j}$ refers to the influence coefficient of corporate stakeholder $j$ to stakeholder $i, a_{i j} f_{i j}\left(V_{j i}\right)$ refers to the influence of stakeholder $j$ on the population density of stakeholder $i$, that is, the effect of income of value-added. The model can describe the symbiotic relationship among the $n$ stakeholders and their evolution. The symbiosis evolution model of enterprise stakeholders is composed of multiple nonlinear equations. The quantity of specific equations is determined by the number of enterprise stakeholders. The model can be used to analyze the symbiosis evolution of any two or more stakeholders. The parameters of the model can be estimated by mathematical methods.

\section{Dynamic Mechanism of the Model}

To explain the dynamic mechanism of the symbiosis evolution model, the evolution process of stakeholder population density (income of value-added) in symbiosis should be described. For convenience, this paper chooses the two core stakeholders, i.e., the shareholders and the employees as an example and studies their symbiosis and evolution process.

\subsection{The Expansion of Symbiotic Evolution Model of Shareholders and Employees}

According to the above discussions, the symbiosis evolution model for the shareholders and the employees changes over time which leads to a dynamic development process. To clarify the change and explain its dynamic mechanism, Equation (3) needs to be transformed:

$$
\left\{\begin{array}{l}
\frac{d V_{1}}{d t}=r_{1}\left(1+a_{12} f_{12}\left(V_{2}\right)\right) * V_{1}\left[\frac{K_{1}\left(1+a_{12} f_{12}\left(V_{2}\right)\right)-V_{1}}{K_{1}\left(1+a_{12} f_{12}\left(V_{2}\right)\right)}\right. \\
\frac{d V_{2}}{d t}=r_{2}\left(1+a_{21} f_{21}\left(V_{1}\right)\right) * V_{2}\left[\frac{K_{2}\left(1+a_{21} f_{21}\left(V_{1}\right)\right)-V_{2}}{K_{2}\left(1+a_{21} f_{21}\left(V_{1}\right)\right)}\right]
\end{array}\right.
$$

Let

$$
\left\{\begin{aligned}
\lambda_{1} & =r_{1}\left(1+a_{12} f_{12}\left(V_{2}\right)\right) \\
\lambda_{2} & =r_{2}\left(1+a_{21} f_{21}\left(V_{1}\right)\right) \\
M_{1} & =K_{1}\left(1+a_{12} f_{12}\left(V_{2}\right)\right) \\
M_{2} & =K_{2}\left(1+a_{21} f_{21}\left(V_{1}\right)\right)
\end{aligned}\right.
$$

Then Formula (5) can be changed into

$$
\left\{\begin{array}{l}
\frac{d V_{1}}{d t}=\lambda_{1} V_{1}\left(1-\frac{V_{1}}{M_{1}}\right) \\
\frac{d V_{2}}{d t}=\lambda_{2} V_{2}\left(1-\frac{V_{2}}{M_{2}}\right)
\end{array}\right.
$$


When there are $n$ stakeholders in an enterprise, the evolution model of any stakeholder $i$ in a symbiotic environment can be expressed as follows:

$$
\frac{d V_{i}}{d t}=\lambda_{i} V_{i}\left(1-\frac{V_{i}}{M_{i}}\right)
$$

In the above formula, $\lambda_{i}=r_{i}\left(1+\sum_{j=1}^{n} a_{i j} f_{i j}\left(V_{j i}\right)\right), M_{i}=K_{i}\left(1+\sum_{j=1}^{n} a_{i j} f_{i j}\left(V_{j i}\right)\right)$. Therefore, the symbiotic development of stakeholders still conforms to the logistic growth model. Equation (7) has a similar form to Equation (1), but with a different meaning. Equation (1) indicates that stakeholders develop independently. In this case, with the assumption of this paper, the natural growth rate $r_{i}$ and the maximum environmental capacity $K_{i}$ of stakeholders are only affected by the factors of their own and are approximately two constants. Equation (7) describes the symbiotic development and mutual influence of stakeholders. In Equation (7), the maximum environmental capacity and natural growth rate of either part are affected by the density of the other's population which leads to two variables changing over time. Here $\lambda_{i}$ represents the symbiotic natural growth rate of the stakeholders, and $M_{i}$ is the maximum capacity that an enterprise can take under the symbiosis environment, that is, the maximum value-added that an enterprise can provide to its stakeholders. The symbiotic natural growth rate $\lambda_{i}$ and the maximum symbiotic environmental capacity $M_{i}$ change with the changing population densities of stakeholders. The symbiotic effect results in the variations of the maximum environmental capacity and the natural growth rate of the population.

\subsection{The Dynamic Mechanism of Symbiotic Evolution Model of Stakeholders}

The above discussion indicates that stakeholders are in a complicated symbiotic relationship with each other in the symbiotic model, and their development is similar to the ecological symbiotic system. The evolutionary trajectory of stakeholders is a dynamic, multi-parameter, time-wise logistic curve, which is shown in Figure 2.

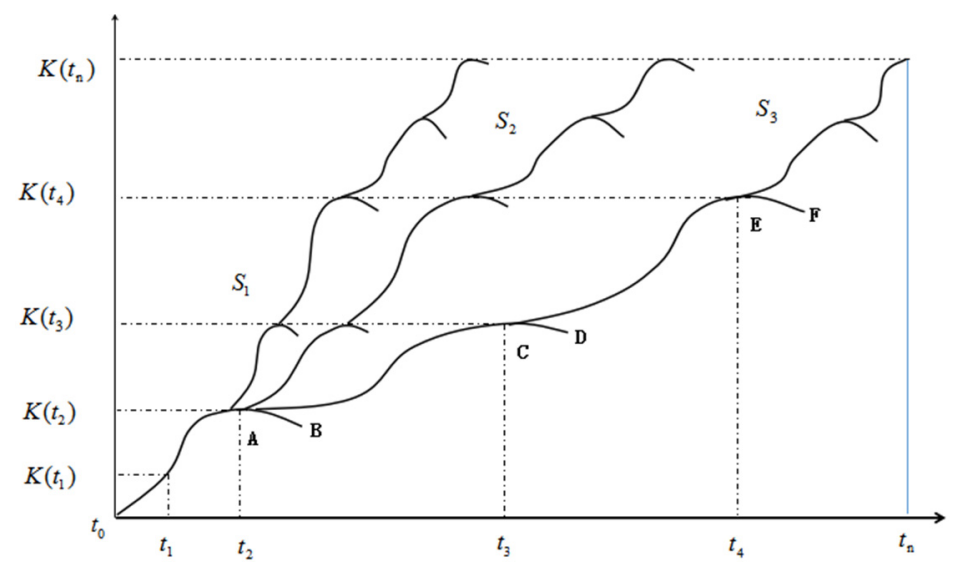

Figure 2. Dynamic chart of stakeholder symbiotic evolution.

In Figure $2, S_{1}, S_{2}$, and $S_{3}$ represent different stakeholder populations respectively. $K\left(t_{1}\right), K\left(t_{2}\right)$, $\ldots K\left(t_{n}\right)$ are the limits that stakeholder populations constantly reach in their development process, which reflect the maximum environment capacities of the population. The stakeholder population will go through the process of starting, accelerating growth, growth rate slowing down, and saturation in each development stage. When it reaches saturation, it might break through the limit of the initial environmental capacity by adapting a certain new mechanism and enter another higher development stage. Alternatively, the population begins to decline and develop in the opposite direction because of the negative inhibiting mechanism. The population symbiosis evolution of the stakeholders is affected by macroeconomic status, enterprise resources, internal and external policy regulation, etc. 
The dynamic mechanisms of symbiosis evolution include benefit-driven mechanism, selection-balance mechanism, synergy mechanism, and policy regulation mechanism. Different mechanisms correspond to different stages of stakeholder evolution in Figure 2.

At the very beginning stage, it is the benefit-driven mechanism that plays a decisive role, corresponding to the time period of $t_{0}-t_{1}$ in Figure 2. Driven by benefits, stakeholders make full use of their respective advantages, for instance, the resources they own, to create enterprise value cooperatively. At this stage, the value-added of the enterprise increases rapidly, and the value-added income of stakeholders shows exponential growth. At the same time, the benefit-driven mechanism is also the dominating force to stimulate the innovation of enterprise. When the population of stakeholders reaches the saturation stage, the benefit-driven mechanism could work together with the synergy mechanism in stimulating the increase of enterprise value and continuously breaking the limits and enter another growing stage. Due to the constraints of enterprise resources and the number of its own population, the growth rate of value-added income of all stakeholders will slow down at a certain time. Without the impact of the factors that could lead to a breakthrough on the environment capacity, for example, if excluding the expansion of environmental capacity brought by innovation, the value-added income of all stakeholders will gradually reach their maximum. This stage corresponds to $t_{1}-t_{2}$ in the dynamic mechanism diagram, and the dominating mechanism is the selection-balance mechanism.

Compared with the positive promoting effect of the benefit-driven mechanism, the selection-balance mechanism has a negative inhibiting effect on the symbiotic development of shareholders and employees. The selection-balance mechanism selects symbiotic units in the symbiotic system by some standards [46,47]. Normally, the symbiotic system will choose the symbiotic unit with higher adaptability and eliminate the low, to maintain the balance of the symbiotic system and promote the development of it. From the perspective of symbiotic units, this process is represented that the symbiotic units take various strategies to compete for the limited resources for their own development under the given environmental capacity, thus resulting in the crowding among the populations. The selection-balance mechanism is a self-sustaining mechanism for stakeholders in the enterprise. When the scale of an enterprise develops to a certain extent, influenced by various internal and external factors, the contradiction between the finiteness of enterprise resources and the infinity of various resource demands of various stakeholders makes the stakeholders compete for the limited resources. Under the selection-balance mechanism, the competition behavior of stakeholders is not only happening among different stakeholder groups, for instance between shareholders and employees, but also within the same stakeholder group, for instance, among individuals in the employee group. Affected by the selection-balance mechanism, the growth rate of the stakeholder population diminishes to zero, then the population reaches the maximum that the environment can undertake, corresponding to the halt of value-added income of the stakeholder.

The synergy mechanism is the key mechanism for stakeholders to break through environmental capacity constraints. Synergy mechanism has a positive effect on the increase of stakeholder population and environmental capacity. The positive effect can be explained in two aspects: Firstly, according to the synergy theory proposed by Hermann Haken in 1969, synergism can better explain the dynamic movement of an organization from disorder to order. Synergy mechanism can bring higher efficiency and better utilization of resources as well [48]. It takes full advantage of stakeholder resources and facilitates the break-through of the limit on stakeholder population density by jointly allocating resources. In the practice of symbiotic governance, the synergy mechanism indicates that stakeholders invest various resources into enterprises and integrate these resources into a value-creating and sharing environment. All relevant stakeholders work together to create enterprise value and improve value-added. The increase of value-added means that the environment capacity of stakeholders is enlarged, and leads to the increase of value-added income of stakeholders. In the symbiotic evolution model of stakeholders established in this paper, the synergy mechanism makes the symbiotic coefficient $a_{i j}>0$, and the stakeholders are in the mutual benefit symbiosis model. Under the synergy mechanism, 
the population density of each stakeholder is acceleraholders. Secondly, synergy is conducive to innovation. Innovation is the source power of evolutionary economics and the direct power for enterprises to break through the original environment capacity [49]. Innovators will benefit from the innovation before other competitors complete the imitation. innovation gradually develops from the behavior of individual entrepreneurs to the behavior of $R \& D$ teams in large enterprises. The main body of innovation changes from individual to the collective, and innovation is a kind of cooperative behavior [46]. Synergy mechanism works through innovation and increases the value-added income of stakeholders in the symbiotic system. With the action of benefit-driven mechanism and synergy mechanism, the environmental capacity of the stakeholder population increased from $K\left(t_{1}\right)$ to $K\left(t_{2}\right)$, corresponding to the $t_{1}-t_{2}$ period in Figure 2. Since then, with the action of these two positive feedback mechanisms, the population density of stakeholders has developed continuously, corresponding to the $t_{2}-t_{n}$ stage in Figure 2. At the same time, the environmental capacity of the population gradually expanded to $K\left(t_{n}\right)$.

The effect of the policy regulation mechanism runs through the whole symbiotic process of $t_{0}-t_{n}$. It affects the population density together with the benefit-driven mechanism, selection-balance mechanism, and synergy mechanism. Policy regulation includes both macro-control and micro policy regulations. The policy regulation mechanism can either positively or negatively affect the creation of value-added enterprises. When the policy regulation mechanism is consistent with the mechanism that could promote the development of the population, the growth of the population density is accelerated and the limit of the original environment capacity can be broken through quickly to enter the next stage of symbiosis development. When the policy regulation mechanism is consistent with the negative mechanism, it will slow down the population growth rate and even make the population density evolve following the directions of $A B, C D$, and $E F$ in Figure 2.

In summarize, the symbiotic system of stakeholders evolves and develops under the influence of benefit-driven mechanisms, selection-balance mechanisms, synergy mechanisms, and policy regulation mechanisms. In the long run, the symbiosis relationship of stakeholders could make the value-added of enterprises increase continuously given that a positive mechanism dominates the process. As a result, the value-added income of stakeholders increases as well.

\section{Numerical Simulation Analysis}

When the symbiotic mechanism acts in a symbiotic system, its impacts on each symbiotic unit are different, which results in different symbiotic modes. With different symbiosis modes, the stakeholder densities have various development paths and produce different results. Based on the analysis above, the symbiosis model of stakeholders can be quantified by the symbiosis coefficient. To describe the symbiosis and evolution process of stakeholders in various modes, the research method of numerical simulation can be used. Numerical simulation can not only overcome the difficulties of empirical research in dynamic large sample data collection but also show the symbiotic evolution process of stakeholders vividly and systematically.

\subsection{Stability Analysis of Equilibrium Point of the Model}

The symbiosis of stakeholders is a dynamic system, and its symbiosis process is an evolutionary dynamic process. To study the process, the stability of the equilibrium point of the model needs to be studied $[50,51]$. The evolution processes of shareholders and employees are used as the specific application of the symbiotic evolution model.

$$
\left\{\begin{array}{l}
\phi\left(V_{1}(t), t\right)=\frac{d V_{2}(t)}{d t}=r_{2} V_{2}\left[1-\frac{V_{2}}{K_{2}}+\alpha \frac{V_{1}}{K_{1}}\right] \\
\phi\left(V_{2}(t), t\right)=\frac{d V_{2}(t)}{d t}=r_{2} V_{2}\left[1-\frac{V_{2}}{K_{2}}+\alpha \frac{V_{1}}{K_{1}}\right]
\end{array}\right.
$$

Let $\varphi\left(V_{1}(t), t\right)=0, \varphi\left(V_{2}(t), t\right)=0$, the equilibrium point of symbiosis and evolution of shareholders and employees are as follows: $E_{1}(0,0), E_{2}\left(K_{1}, 0\right), E_{3}\left(0, K_{2}\right), E_{4}\left(\frac{K_{1}(1+\alpha)}{1-\alpha \beta}, \frac{K_{2}(1+\beta)}{1-\alpha \beta}\right)$. Due to 
the nonlinear characteristics of the symbiotic evolution model, it is necessary to use the Lyapunov discriminant method to judge the stability of the system. In this paper, the Jacobian matrix is established to test the stability of the local equilibrium point of the model. The Jacobian matrix of the model is as follows:

$$
\left[\begin{array}{cc}
\frac{\phi \varphi_{1}}{\phi V_{1}} & \frac{\phi \varphi_{2}}{\phi V_{1}} \\
\frac{\phi \varphi_{1}}{\phi V_{2}} & \frac{\phi \varphi_{2}}{\phi V_{2}}
\end{array}\right]=\left[\begin{array}{cc}
r_{1}\left(1-2 \frac{V_{1}}{K_{1}}+\alpha \frac{V_{2}}{K_{2}}\right) & r_{1} \alpha \frac{V_{1}}{K_{2}} \\
r_{2} \beta \frac{V_{2}}{K_{1}} & r_{2}\left(1-2 \frac{V_{2}}{K_{2}}+\beta \frac{V_{1}}{K_{1}}\right)
\end{array}\right]
$$

When the determinant of the Jacobian matrix, represented by $\operatorname{Det}(\mathrm{J})$, is greater than 0 and the trace, represented by $\operatorname{Tr}(\mathrm{J})$, is less than 0 , the local equilibrium point is stable. By substituting local equilibrium points with $E_{1}, E_{2}, E_{3}$, and $E_{4}$, the $\operatorname{Det}(J)$ and $\operatorname{Tr}(J)$ of the Jacobian matrix at the equilibrium point can be obtained, the results are shown in Table 2.

Table 2. Local equilibrium points and stability conditions of symbiotic evolution model of shareholders and employees.

\begin{tabular}{cccc}
\hline Equilibrium Point & Det $(\mathrm{J})$ & $\operatorname{Tr}(\mathrm{J})$ & Stability Condition \\
\hline $\mathrm{E} 1(0,0)$ & $r_{1} r_{2}$ & $r_{1}+r_{2}$ & instability \\
\hline $\mathrm{E} 2\left(K_{1}, 0\right)$ & $-r_{1} r_{2}(1+\beta)$ & $-r_{1}+r_{2}(1+\beta)$ & $\beta<-1$ \\
\hline $\mathrm{E} 3\left(0, K_{2}\right)$ & $-r_{1} r_{2}(1+\alpha)$ & $-r_{1}+r_{2}(1+\alpha)$ & $\alpha<-1$ \\
\hline $\mathrm{E} 4\left(\frac{K_{1}(1+\alpha)}{1-\alpha \beta}, \frac{K_{2}(1+\beta)}{1-\alpha \beta}\right)$ & $\frac{r_{1} r_{2}(1+\alpha)(1+\beta)}{1-\alpha \beta}$ & $\frac{-r_{1}(1+\alpha)-r_{2}(1+\beta)}{1-\alpha \beta}$ & $\alpha>-1, \beta>-1$ \\
\hline
\end{tabular}

\subsection{Numerical Simulation of Symbiotic Evolution Model of Shareholders and Employees}

The numerical simulation of the stakeholder symbiosis model assigns the parameters of the model based on the experience of large enterprises in China. Based on previous research [7], we assume that the growth rate of population resources of shareholders and employees in the symbiosis evolution model is 0.05 and 0.15 , respectively, and assuming the maximum environmental capacity is 1000 , the initial population density is 100 and the evolution cycle is 800 for both shareholders and employees. Various values are given to the symbiosis coefficients $\alpha$ and $\beta$ to simulate different evolution tracks of shareholders and employees with different symbiosis modes.

(1) Independent symbiotic model: In this model, $\alpha=\beta=0$. Shareholders and employees are independent. Their evolution processes do not affect each other. The scale of the population density is only related to their natural growth rate. When the two groups are in equilibrium, their scales are the upper limits for independent symbiotic model. The evolution of the population densities for shareholders and employees are shown in Figure 3.

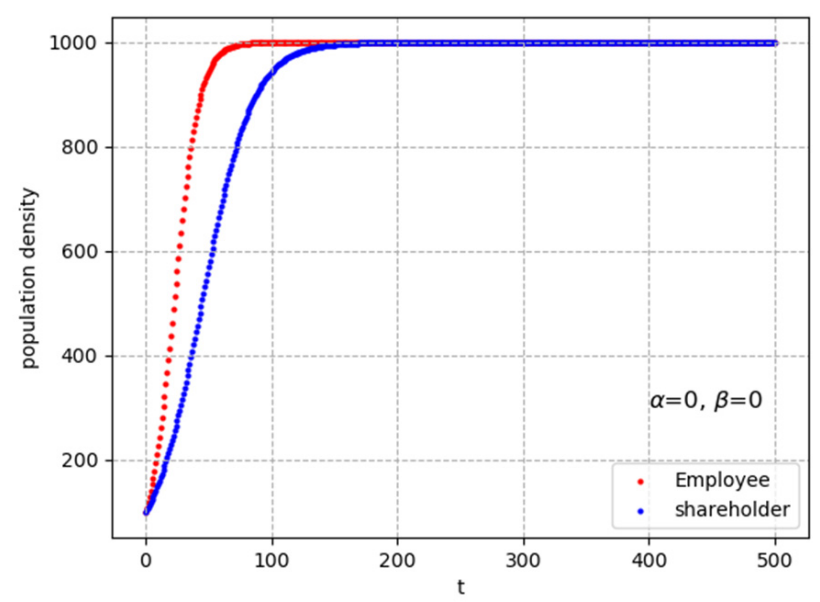

Figure 3. Independent symbiosis model. 
(2) Partial benefit symbiosis model. At this time, $\alpha=0, \beta>0$, or $\alpha>0, \beta=0$. The development of one side whose symbiosis coefficient is 0 is not affected by the other side, and the maximum stable scale is the upper limit of its independent development. The development of one side whose symbiosis coefficient is greater than 0 benefits from the other side and the maximum stable scale is greater than the upper limit of its own independent development. The evolution track of partial benefit symbiosis is shown in Figure 4.

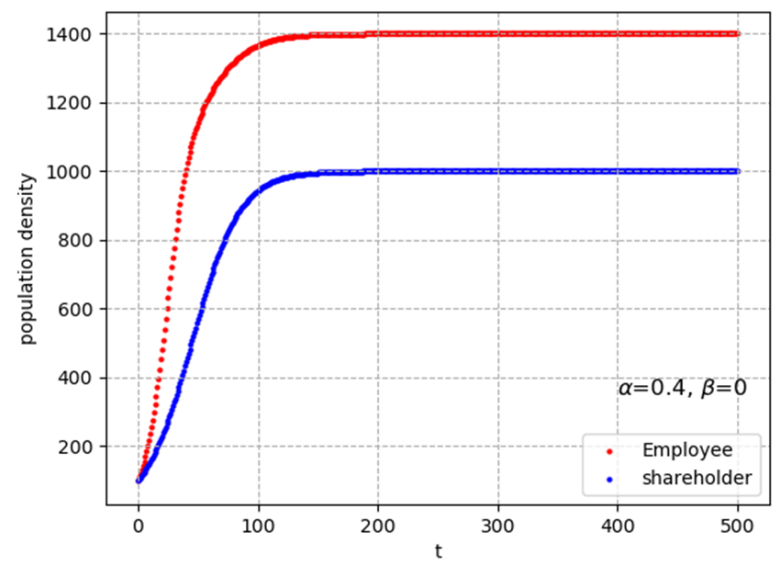

Figure 4. Partial benefit symbiosis model.

(3) Competitive symbiosis model. This model requires the symbiosis coefficient of both shareholders and employees to be less than 0 , and the development of both groups will have a negative impact on each other, and the maximum stable scale of both groups is less than the upper limit of their own independent development. The evolution track of the competitive symbiosis model is shown in Figure 5.

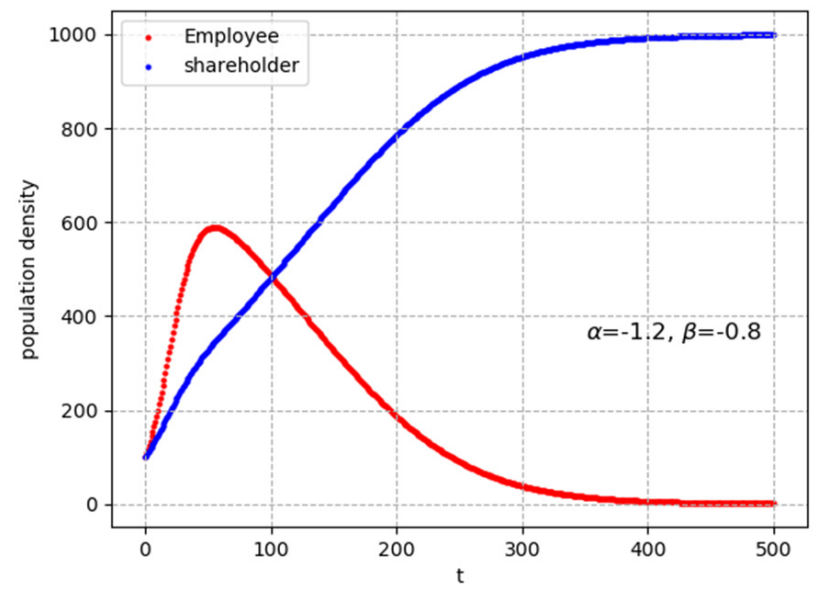

Figure 5. Competitive symbiosis model.

(4) Parasitic symbiosis model. In the symbiotic evolution model of shareholders and employees, the symbiotic coefficient of the parasite is greater than 0 , and that of the host is less than 0 . The host is affected by the consumption of the parasite, the maximum stable scale of it is smaller than the upper limit of independent development. The parasite benefits from the host, so the maximum stable scale is larger than the upper limit of its own independent development. The evolution track of the parasitic symbiosis model is shown in Figure 6. 


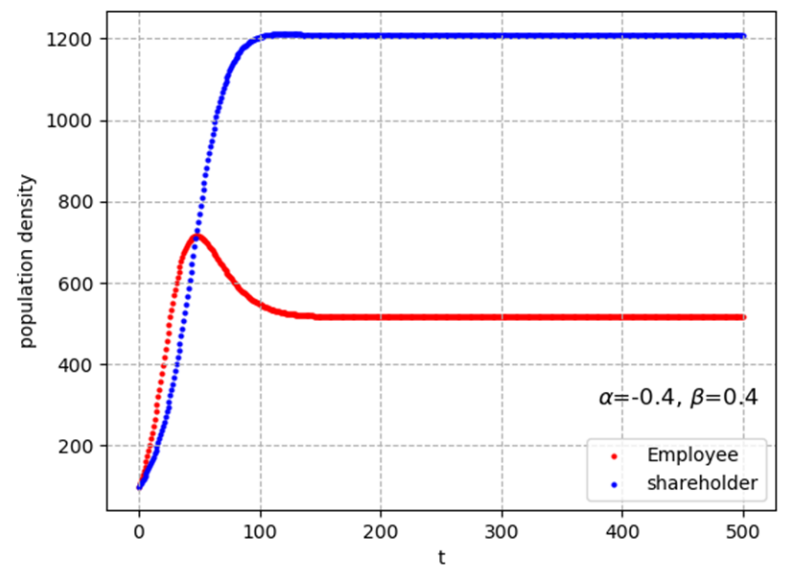

Figure 6. Parasitic symbiosis model.

(5) Mutual benefit symbiosis model. In this model, the symbiosis coefficient between shareholders and employees is greater than 0 . Mutual benefit symbiosis model can be divided into two forms because the symbiosis coefficients of symbiosis units may or may not be equal. When the symbiosis coefficients of shareholders and employees are equal, this is symmetric mutual benefit symbiosis model. When the symbiosis coefficients of shareholders and employees are not equal, this is asymmetrical mutual benefit symbiosis model. Under mutual benefit symbiosis model, both shareholders and employees can provide benefits for each other, and the final stable scale of the two populations is larger than the upper limit of independent development. In this model, the symbiotic system can break through environmental constraints and expand environmental capacity through collaboration and innovation. The evolution tracks of the symbiosis model of shareholders and employees are shown in Figures 7 and 8, respectively.

Symmetric mutual benefit symbiosis model is the most efficient and stable symbiosis model. And it is the ideal symbiotic model between shareholders and employees. From the perspective of economics and management, in this model, both shareholders and employees can benefit from each other's behavior. The symbiotic parties can generate new added value and distribute according to the symmetry mechanism. The evolution of both parties is synchronous. This is the best embodiment of corporate social responsibility. In management practice, the symmetric mutual model is also regarded as the most ideal symbiosis behavior model pursued by enterprises, under which both employers and employees should try their best to develop together.

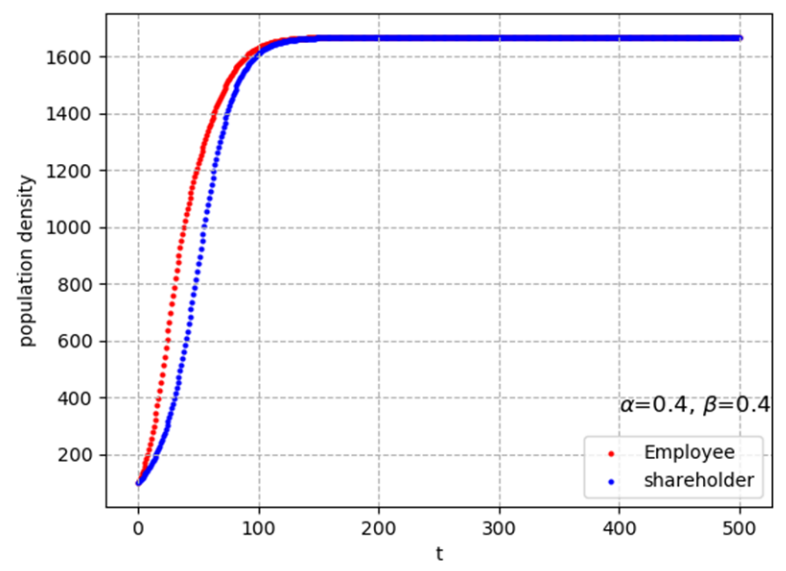

Figure 7. Symmetric mutual benefit symbiosis model. 


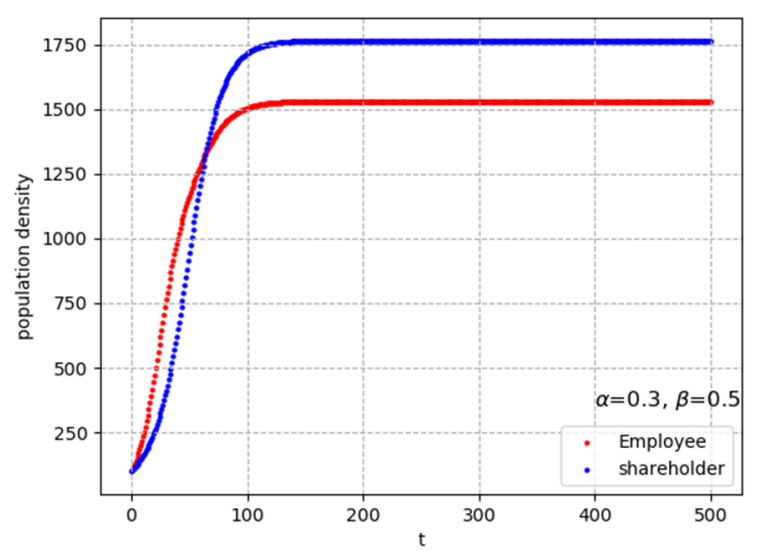

Figure 8. Asymmetrical mutual benefit symbiosis model.

\section{Discussion}

The above theoretical analysis and simulation results show that stakeholders participate in enterprise governance in the development of an enterprise. They create and share the value-added of the enterprise. The allocation of value-added among stakeholders can be described by the symbiotic evolution model of stakeholders. This is the embodiment of corporate social responsibility. In a limited period of time, the stakeholder population which is measured by the value-added income increases with a natural growth rate which is approximately constant, and finally reaches the upper limit due to finite resources. The development of the stakeholder population conforms to the logistic growth curve. With less stringent time constraints, when the stakeholders are in symbiosis model, the natural growth rate and the maximum environmental capacity of each stakeholder population are not constant, but a variable that changes with time due to the influences from the other populations.

The dynamic mechanisms that dominate the symbiosis and evolution process of stakeholders include benefit-driven mechanism, selection-balance mechanism, synergy mechanism, and policy regulation mechanism. In the primary stage of symbiosis development, the benefit-driving mechanism plays a leading role, the population density (income of value-added) of stakeholders is in an accelerating growth stage. The competition among stakeholders increases as the increasing population density. With the finite added-value of an enterprise, the selection-balance mechanism begins to play a leading role, which decreases the growth rate of the value-added income of stakeholders and turns the growth rate into zero at the end. With the effect of this mechanism, the population density of stakeholders reaches its upper limits which are related to environment capacity. To break through the limit of the original environment capacity, the stakeholders need to make full use of the advantages of symbiosis model. The synergetic mechanism plays a major role through a series of synergetic behaviors such as complimentary advantageous resources and division of labor among stakeholders. Synergy produces and promotes innovation [48]. Stakeholder groups can break through the original environment capacity limit and enter a new stage of growth with higher environmental capacity. The policy regulation mechanism accompanies the whole process of the symbiosis and evolution of stakeholders and can promote and inhibit the development of the symbiosis process. At different stages of the symbiosis, the mechanisms that play a leading role are different. The development of stakeholders is pushed forward by these four motivation mechanisms alternately.

There are five symbiosis modes: independent symbiosis model, competitive symbiosis model, parasitic symbiosis model, partial benefit symbiosis model, and mutual benefit symbiosis model. By using numerical simulation on different models of the shareholders and employees, the two core stakeholders of an enterprise, the evolutionary trajectories and the final scales of the population (value-added income) of shareholders and employees in different symbiosis modes can be obtained. The simulation results show that the mutual benefit symbiosis model is the optimal model for stakeholders regarding the value-added income. This model can well reflect the corporate social responsibility and 
realize the long-term sustainable development of enterprises. In the practice of management, enterprises can adjust the symbiosis model according to the actual data of their value-added allocation among stakeholders, and make the symbiosis model turn to be mutually beneficial.

Under the background that CSR is widely concerned, the management enlightenment of corporate stakeholder symbiosis governance lies in: in the process of the development, enterprises should make full use of the logistic growth law of stakeholder population and accurately understand the symbiotic evolution law; the dynamic mechanism of stakeholders' symbiosis and evolution should be coordinated reasonably, and the economic driving mechanism should also be used to promote the development of the symbiotic system. When the population in a symbiotic system reaches, or nearly reaches, the environmental capacity of an enterprise, the enthusiasm of stakeholders to carry out collaborative innovation should be mobilized, so that the synergy mechanism of the system can be activated and play an important role in breaking through the original environmental capacity, thus, making the enterprise enter into a higher level of symbiosis system. With this methodology, enterprises can achieve sustainable development and CRS goals.

\section{Conclusions}

This paper integrates the symbiosis theory and evolution theory into stakeholder governance research and constructs a stakeholder Symbiosis Evolution Model by taking corporate social responsibility as the background of stakeholder theory. By using the logistic model that describes the growth of species in biology, the symbiosis evolution model of enterprise stakeholders is established, and the corresponding dynamic mechanism of the model is also studied. The symbiosis evolution of shareholders and employees are taken as the specific application to test the model. Their evolution processes in different symbiosis modes are studied by performing a numerical simulation based on the stability analysis of the equilibrium point of the model. The results show that: there are six symbiotic modes in the stakeholder symbiotic evolution system. independent symbiotic model, partial benefit symbiosis model, symmetric mutual benefit symbiosis model, asymmetrical mutual benefit symbiosis model, parasitic symbiosis model, competitive symbiosis model, respectively. Symmetric mutualism benefit model can well ensure the sustainable development of enterprises and reflect the corporate social responsibility goals of enterprises, which is the best symbiosis model for stakeholders. There are four dynamic mechanisms in the stakeholder symbiosis system, which are benefit-driven mechanism, selection-balance mechanism, synergy mechanism, and policy regulation mechanism. The stakeholder symbiotic evolution system is developing under these four mechanisms.

The stakeholder symbiosis model proposed in this paper is a long-term and sustainable development model. Therefore, it needs a long period of time to collect the data to verify the model. Also, the definition of each stage in the model mechanism needs to be further clarified. At present, the research in this paper can only be fulfilled through theoretical analysis and simulation, which is the limitation of this paper.

Based on the existing studies, further research can be carried out as verifying the characteristics of different stages of stakeholder symbiosis with the actual data of enterprises. Considering that the heterogeneity among enterprises will lead to different modes of stakeholder symbiosis, factors such as enterprise-scale and category of the industry should also be taken into account in the process of verifying the model with actual data.

Author Contributions: Conceptualization, D.W., W.Z., and C.Z.; methodology, D.W., W.Z., and C.Z.; investigation, D.W., W.Z., and C.Z.; formal analysis, D.W. and C.Z.; writing-original draft preparation, D.W. and C.Z.; writing-review and editing, Y.W., D.W., and H.L.; funding acquisition, W.Z. and C.Z. All authors have read and agreed to the published version of the manuscript.

Funding: This research was funded by the Natural Science Foundation of Anhui Province Youth Project (in china), grant number 2008085QG340, and Humanities and Social Sciences General Research Project of Ministry of Education (in china), grant number 20YJC630203.

Acknowledgments: We are grateful to Weidong $\mathrm{Xu}$ for his guidance in language writing. 
Conflicts of Interest: The authors declare that they have no conflict of interest.

\section{References}

1. Wiseman, J. An evaluation of environmental disclosures made in corporate annual reports. Account. Organ. Soc. 1982, 7, 53-63. [CrossRef]

2. Al-Abdin, A.; Roy, T.; Nicholson, J.D. Researching corporate social responsibility in the Middle East: The current state and future directions. Corp. Soc. Responsib. Environ. Manag. 2018, 25, 47-65. [CrossRef]

3. Jiang, W.Y.; Wong, J.K. Key activity areas of corporate social responsibility (CSR) in the construction industry: A study of China. J. Clean. Prod. 2016, 113, 850-860. [CrossRef]

4. Lan, L.L.; Heracleous, L. Rethinking agency theory: The view from law. Acad. Manag. Rev. 2010, 35, $294-314$.

5. Falck, O.; Heblich, S. Corporate social responsibility: Doing well by doing good. Bus. Horiz. 2007, 50, 247-254. [CrossRef]

6. Bainbridge, S. Director primacy and shareholder disempowerment. Harv. Law Rev. 2006, 119, 1735-1758.

7. Zhu, W.D.; Zhang, C.; Wu, Y.; Ku, Q.; Zhang, F. Research on Evolving Dynamic Model of Labor-Capital Symbiotic Between Employees and Shareholders: Based on Value-Added and Stakeholder Theory. J. Manag. Sci. China 2019, 22, 112-126. (In Chinese)

8. Mirata, M.; Emtairah, T. Industrial Symbiosis Networks and the Contribution to Environmental Innovation: The Case of the Landskrona Industrial Symbiosis Programme. J. Clean. Prod. 2005, 13, 993-1002. [CrossRef]

9. Wang, Z.L.; Tan, Q.M.; Xu, X.D. The Evolution Model and Empirical Studies of Enterprises Cluster Symbiosis. Chin. J. Manag. Sci. 2006, 14, 42-148. (In Chinese)

10. Taddeo, R.; Simboli, A.; Morganate, A.; Erkman, S. The Development of Industrial Symbiosis in Existing Contexts Experiences from Three Italian Clusters. Ecol. Econ. 2017, 139, 55-67. [CrossRef]

11. Castaldi, C. The relative weight of manufacturing and services in Europe: An innovation perspective. Technol. Forecast. Soc. China 2009, 76, 709-722. [CrossRef]

12. Zhang, W.; Liu, P.F.; Zhang, J.K. Multi-Group Symbiotic Evolution Mechanism in an Innovative Ecosystem: Evidence from China. Rev. Cercet. Si Interv. Soc. 2019, 66, 249-277. [CrossRef]

13. Hodgson, G.H.; Huang, K.N. Evolutionary economics and evolutionary game theory: Are they a different species? J. Evol. Econ. 2012, 22, 346-365. [CrossRef]

14. Zhu, W.D.; Wang, J. The Relative Relationship Between Employees Income Rate and Enterprise Value Based on Value Added. Metal. Int. 2013, 18, 49-52.

15. Brown, J.A.; Forster, W.R. CSR and Stakeholder Theory: A Tale of Adam Smith. J. Bus. Ethics 2013, 112, 301-312. [CrossRef]

16. Russo, A.; Perrini, F. Investigating Stakeholder Theory and Social Capital: CSR in Large Firms and SMEs. J. Bus. Ethics 2010, 91, 207-221. [CrossRef]

17. Freeman, R.E.; Dmytriyev, S. Corporate Social Responsibility and Stakeholder Theory: Learning From Each Other. Emerg. Issues Manag. 2017, 2, 7-15. [CrossRef]

18. Carroll, A.B. The pyramid of corporate social responsibility: Toward the moral management of organizational stakeholders. Bus. Horiz. 1991, 34, 39-48. [CrossRef]

19. Glavas, A. Corporate social responsibility and employee engagement: Enabling employees to employ more of their whole selves at work. Front. Psychol. 2016, 7, 796. [CrossRef]

20. Gangone, A.D.; Ganescu, M.C. Corporate social responsibility in emerging and developing economies in Central and Eastern Europe-A measurement model from the stakeholder theory perspective. Econ. Res. Ekon. Istraživanja 2014, 27, 539-558. [CrossRef]

21. Ganescu, C.; Gangone, A. A model of socially responsible organizational culture. Studia Univ. Vasile Goldis Arad. Econ. Ser. 2017, 27, 45-59. [CrossRef]

22. Ramesh, K.; Saha, R.; Goswami, S.; Dahiya, R. Consumer's response to CSR activities: Mediating role of brand image and brand attitude. Corp. Soc. Responsib. Environ. Manag. 2019, 26, 377-387. [CrossRef]

23. Baskentli, S.; Sen, S.; Du, S.; Bhattacharya, C.B. Consumer reactions to corporate social responsibility: The role of CSR domains. J. Bus. Res. 2019, 95, 502-513. [CrossRef]

24. Dospinescu, N.; Dospinescu, O.; Tatarusanu, M. Analysis of the Influence Factors on the Reputation of Food-Delivery Companies: Evidence from Romania. Sustainability 2020, 12, 4142. [CrossRef] 
25. Nadanyiova, M.; Durana, P. Corporate social responsibility as a brand value-enhancing tool. In Proceedings of the 8th International Scientific Symposium Economy of Eastern Croatia-Vision and Growth, Osijek, Croatia, 30-31 May 2019; pp. 1225-1237.

26. Freeman, E.R. Strategic Management: A Stakeholder Approach; Pitman Publishing: Boston, MA, USA, 1984.

27. Friedman, M. The social responsibility of business is to increase its profits. N. Y. Times Mag. 1970, 13, $235-251$.

28. Freeman, R.E.; Phillips, R.A. Stakeholder theory: A libertarian defense. Bus. Ethics Q. 2002, 12, 331-349. [CrossRef]

29. Fama, E.F. Agency problems and the theory of the firm. J. Political Econ. 1980, 88, 288-307. [CrossRef]

30. Gossman, S.J.; Hart, O.D. The Costs and Benefits of Ownership: A Theory of Vertical and Lateral Integration. J. Political Econ. 1986, 94, 691-719. [CrossRef]

31. Mitchell, A.; Wood, D. Toward a Theory of Stakeholder Identification and Salience: Defining the Principle of Who and What Really Counts. Acad. Manag. Rev. 1997, 22, 853-886. [CrossRef]

32. Aoki, M. Co-Operative Game Theory of the Firm; Oxford University Press: Oxford, UK, 1987.

33. O'Connor, M.A. The Human Capital Era: Reconceptualizing Corporate Law to Facilitate Labor-Management Cooperation. Cornell Law Rev. 1993, 78, 899-965.

34. Wood, D.J.; Jones, R.E. Stakeholder Mismatching: A Theoretical Problem in Empirical Research on Corporate Social Performance. Int. J. Organ. Anal. 1995, 7, 229-267. [CrossRef]

35. Sun, T.Q. The Structure of Industrial Organization Research: Oligarchs, Big, Medium and Small Symbiosis; Economic Science Press: Beijing, China, 2001.

36. Clarkson, M.E. Stakeholder Framework for Analyzing and Evaluating Corporate Social Performance. Acad. Manag. Rev. 1995, 20, 92-117. [CrossRef]

37. John, R.; Eric, S. Shareholder Interests, Human Capital Investment and Corporate Governance; Research Paper No. 1631; Stanford University, Graduate School of Business: Stanford, CA, USA, 2000.

38. Rajan, R.G.; Luigi, Z. Power in a Theory of the Firm. Q. J. Econ. 1998, 113, 387-432. [CrossRef]

39. Rajan, R.G.; Luigi, Z. The Firm as a Dedicated Hierarchy: A Theory of the Origins and Growth of Firms. Q. J. Econ. 2001, 116, 805-851. [CrossRef]

40. Maunder, K.T. The decision relevance of value added reports. Maandbl. Voor Account. Bedrijfsecon. 1981, 55, 65-81. [CrossRef]

41. Meek, G.; Gray, S. The Value Added Statement: An Innovation for U. S. Companies. Account. Horiz. 1988, 2, 73-81.

42. Machado, M.A.V.; da Silva, M.A.; Machado, M.R. Analysis of the Relevance of Information Content of the Value Added Statement in the Brazilian Capital Markets. Rev. Contab. Finanç. 2015, 26, 57-69. [CrossRef]

43. Zhu, W.D.; Zhang, C.; Wu, Y.; Tan, Y.F. The Research on Value-Added Report Based on Value Co-Creation and Co-Share Perspective. Account. Res. 2018, 8, 20-27. (In Chinese)

44. Karpik, P.; Belkaoui, A. The Relative Relationship Between Systematic and Value Added Variables. J. Int. Financ. Manag. Account. 2007, 1, 259-276. [CrossRef]

45. Yang, C.Q.; Zhu, W.D. Value-Added Distribution Pattern and Its Determinant Factors Analysis- Empirical Study Based on China Listed Company. Chin. J. Manag. Sci. 2015, 23, 141-150. (In Chinese)

46. Nelson, R.R.; Winter, S.G. An Evolutionary Theory of Economic Change; Belknap Press: Boston, MA, USA, 1982.

47. Hanusch, H.; Pyka, A. Principles of Neo-Schumpeterian Economics. Camb. J. Econ. 2006, 31, 275-289. [CrossRef]

48. Haken, H. Can Synergetics Be of Use to Management Theory? Self-Organ. Manag. Soc. Syst. 1984, $26,33-41$.

49. Huang, K.N. Evolutionary Games and Evolutionary Economics. Econ. Res. J. 2009, 44, 132-145. (In Chinese)

50. Samuelson, L.; Zhang, J.B. Evolutionary Stability in Asymmetric Games. J. Econ. Theory 1992, 57, 363-391. [CrossRef]

51. Yao, Y.H.; Zhou, H.P. The dynamic equilibrium and simulation of mobile internet platform innovation ecosystem a symbiotic evolution model. Kybernetes 2016, 45, 1406-1420. [CrossRef]

Publisher's Note: MDPI stays neutral with regard to jurisdictional claims in published maps and institutional affiliations. 